\title{
Chapter 11 \\ Applying Occupational Health Theories to Educator Stress: Contribution of the Job Demands-Resources Model
}

\author{
Toon W. Taris, Peter L.M. Leisink, and Wilmar B. Schaufeli
}

\begin{abstract}
The first part of this chapter discusses the Job Demands-Resources (JD$\mathrm{R})$ model in general terms. We address several variations of the model, including the JD-R model of burnout and the revised JD-R model. Moreover, we discuss several extensions of the model (engagement, performance and personal characteristics). The evidence for these models is presented and discussed. The second part of the chapter focuses on the application of the model in the context of educator stress. Based on a literature search and the JD-R framework, we provide an overview of the most important findings on the task-specific, organizational and personal antecedents and consequences of educator stress. We conclude that in spite of its considerable promise as a heuristic tool in research on educator stress, as yet the potential of the JD-R model has not fully been exploited.
\end{abstract}

Keywords Educators $\bullet$ Stress $\bullet$ Job demands-resources model $\bullet$ Burnout $\bullet$ Review

- Engagement

\footnotetext{
T.W. Taris $(\bowtie)$

Department of Social, Health and Organizational Psychology, Utrecht University,

Utrecht, The Netherlands

e-mail: t.taris@uu.nl

P.L.M. Leisink

School of Governance, Utrecht University, Utrecht, The Netherlands

e-mail: p.l.m.leisink@uu.nl

W.B. Schaufeli

Department of Social, Health and Organizational Psychology, Utrecht University, Utrecht, The Netherlands

Research Unit Occupational \& Organizational Psychology and Professional Learning, University of Leuven, Leuven, Belgium

e-mail: w.schaufeli@uu.nl
} 


\subsection{The Job Demands-Resources Model}

One of the most popular models in occupational health psychology is the Job Demands-Resources (JD-R) model (Demerouti, Bakker, Nachreiner, \& Schaufeli, 2001). The current version of the model describes the relations among work characteristics (job demands and job resources) and work outcomes (especially health, well-being, motivation and work performance), taking personal characteristics (e.g., self-efficacy, resilience and personality characteristics) into account (Taris \& Schaufeli, 2016, for an overview). At the heart of the model lie three basic assumptions. Firstly, the presence of high levels of job resources is presumed to lead to high job performance through high levels of motivation (this is the motivational process). Secondly, the presence of high levels of job demands is expected to lead to negative health outcomes through high levels of strain (the health impairment process). Thirdly, job demands and job resources are presumed to interact. On the one hand, the adverse effects of high levels of demands on strain and health should be mitigated by the presence of high levels of resources. On the other hand, the combination of high levels of resources and high levels of demands should result in challenge and even higher levels of motivation than would be expected on the basis of the main effects of demands and resources (the interaction hypothesis).

Since its publication in 2001 by Demerouti et al., the JD-R model has been amended and extended several times. In its earliest version, the model focused exclusively on the dimensions of burnout as its main outcomes, but later incarnations also focused on work engagement, employed more diverse outcome variables, and included personal characteristics as well. In this chapter, we first discuss the original JD-R model and its subsequent modifications in greater detail. We then focus on the application of the model in the educator context.

\subsubsection{The Job Demands-Resources Model of Burnout}

The Job Demands-Resources model was initially developed to account for the work-related antecedents of burnout. In their (2001) publication, Demerouti and colleagues started from Lee and Ashforth's (1996) distinction between job demands and job resources, combined with the structural model of burnout that had earlier been proposed by Maslach, Jackson, and Leiter (1996, p. 36). Following previous theorizing on the core dimensions of burnout, Demerouti and colleagues focused on exhaustion/fatigue as a form of strain/ill-health, and cynicism/withdrawal as a form of lack of motivation (e.g., Schaufeli \& Taris, 2005).

Demands and Resources Demerouti et al. (2001) proposed that job demands were "those physical, social, or organizational aspects of the job that require sustained physical or mental effort and are therefore associated with certain physiological and psychological costs" (p. 501). A similar definition was given for job resources: these refer to "those physical, social or organizational aspects of the job that may do any 
of the following: (a) be functional in achieving work goals; (b) reduce job demands and the associated physiological and psychological costs; (c) stimulate personal growth and development" (p. 501). Interestingly, according to these definitions, demands and resources must be distinguished in terms of their effects. Whereas demands are associated with increased "physiological and psychological costs" and have adverse effects in general, resources have generally positive effects. However, these definitions of demands and resources are not mutually exclusive. For example, whereas dealing with certain demands may well require mental effort, this could also result in personal growth and development (Frese \& Zapf, 1994).

Further, the effect of a particular demand or resource may be contingent upon its quantity in a particular job. For instance, autonomy is usually considered an important resource that facilitates both task performance and well-being. However, having too much of this resource is associated with negative outcomes (Warr, 2007), suggesting that at (very) high levels autonomy may work as a job demand. Similarly, whereas social support is usually conceived of as a valuable job resource, high levels of support may have adverse effects on health and well-being (Semmer \& Beehr, 2014). Indeed, even within the cluster of job demands a distinction between "challenge" and "hindrance" demands may be made, with the latter type of demands corresponding with the conceptualization of demands as having adverse outcomes and the first type of demands resembling a job resource (Van den Broeck, De Cuyper, De Witte, \& Vansteenkiste, 2010). Summarizing, based on their effects on worker health and motivation, it may not always be possible to unequivocally label a job characteristic as either a demand or a resource. Although in practice this conceptual ambiguity usually yields no major problems, the conceptual distinction between demands and resources is not as clear-cut as it initially appeared.

Underlying Processes According to the JD-R model of burnout, two different paths related the two burnout components to the two sets of work characteristics. On the one hand, the model proposed that the need of meeting high job demands would require high levels of effort (Hockey, 1997). Continuous high effort expenditure would lead to psychological and physiological costs, such as high levels of fatigue and a low motivation to continue one's activities. Recovery from fatigue is possible by applying recovery-promoting strategies, such as taking breaks, switching to other tasks, or working more slowly. However, when such strategies cannot be applied (e.g., because performance standards are high in combination with high levels of supervisor control), workers may enter a state of sustained activation (Knardahl \& Ursin, 1985). Ultimately, this could lead to a state of physiological and psychological exhaustion, which is the energetic component of burnout.

On the other hand, the presence of high levels of job resources may assist workers in dealing with the possibly adverse effects of a high-demand work environment, and they could be conducive in meeting the work goals. Conversely, the absence of sufficient resources will trigger a self-protective process in which reduced work motivation and withdrawal from the job (in the form of depersonalization and cynicism) will prevent the occurrence of possible negative effects resulting from the future exhaustion and frustration of being unable to achieve one's work goals, which is the motivational component of burnout. Seen from this perspective, psychological withdrawal serves as a self-protective strategy. 
Although this reasoning suggests that the interaction of demands and resources is central to the development of burnout, Demerouti and colleagues (p. 501) argued that such interactions would rarely occur. That is, previous research on interactions between job characteristics (chiefly following Karasek's, 1979, Job DemandsControl model) had already shown that such interactions tend to be statistically insignificant and practically irrelevant (Taris, 2006). Therefore, Demerouti and coauthors (2001) refrained from including this interaction in the model. The JD-R model of burnout therefore proposed that exhaustion would primarily result from high job demands, and that withdrawal/disengagement would be the result of a lack of resources.

Evaluation of the Job Demands-Resources Model of Burnout The JD-R model of burnout has frequently constituted the basis for empirical research on the antecedents of burnout. Most of these studies provided support for the main effects of job resources and job demands on burnout, showing that whereas high levels of demands were usually associated with high levels of exhaustion, high levels of resources were negatively associated with low levels of cynicism/withdrawal (Alarcon, 2011, for a review). Interestingly, whereas in Demerouti et al.' (2001) seminal publication on the JD-R model the possible interaction between job demands and job resources was largely ignored, research on the JD-R model of burnout has frequently tested this interaction. For example, Bakker, Demerouti, Taris, Schaufeli and Schreurs (2003) found that the adverse effect of high levels of demands on exhaustion was mitigated by high levels of resources. Similarly, the positive effects of high levels of resources on withdrawal/cynicism were weaker in the presence of high job demands. These findings were later confirmed in follow-up research (e.g., Bakker, Demerouti, \& Euwema, 2005; Hansen, Sverke, \& Näswall, 2009), adding some credence to the idea that job demands and job resources interact in affecting levels of burnout.

Although the empirical evidence for the assumptions of the Job DemandsResources model of burnout seems impressive, it should be noted that most studies testing this framework employed cross-sectional designs using self-report data. Thus, although the findings of these studies are consistent with the causal predictions of the JD-R model, strictly speaking they do not provide strong evidence for these assumptions. This is aggravated by the fact that longitudinal studies using the JD-R model of burnout have not unequivocally supported these assumptions. For example, using a two-wave longitudinal design, Diestel and Schmidt (2012) failed to confirm the notion that demands and resources predicted burnout over time.

Further, the evidence for the main effects of demands and resources on burnout is considerably stronger than that for demands $\times$ resources interactions, but this is a common finding in the area of job stress research (Taris, 2006). Taris and Schaufeli (2016) argue that this could be due to the fact that interactions are especially likely to occur when the type of demands, resources and outcomes refer to qualitatively similar concepts, e.g., the adverse effects of high emotional demands on emotional exhaustion may be mitigated by high emotional support (De Jonge \& Dormann, 2006). What is interesting about this reasoning is that it goes against Demerouti 
et al.' (2001) implicit assumption that the qualitative differences among different demands, resources and outcomes can be neglected, since they would all be subject to the same underlying process.

\subsubsection{The Revised Job Demands-Resources Model}

In 2004, Schaufeli and Bakker revised and extended the Job Demands-Resources model of burnout. The revised model included not only burnout (representing strain), but also job engagement (as a motivational concept). The two main dimensions of engagement are vigor (i.e., high levels of energy and resilience) and dedication (a sense of significance, pride and challenge), respectively (Schaufeli \& Bakker, 2010). Further, absorption (being fully concentrated and engrossed in one's work) is the third dimension of engagement. Figure 11.1 presents the revised model graphically.

Two Processes Basically, the revised model consists of two largely independent processes. The energetic or health impairment process holds that the relation between job demands and outcomes (especially health) is mediated by strain. That is, similar to the JD-R model of burnout, the revised model argues that high job demands will result in strain. However, the revised JD-R model argues that both

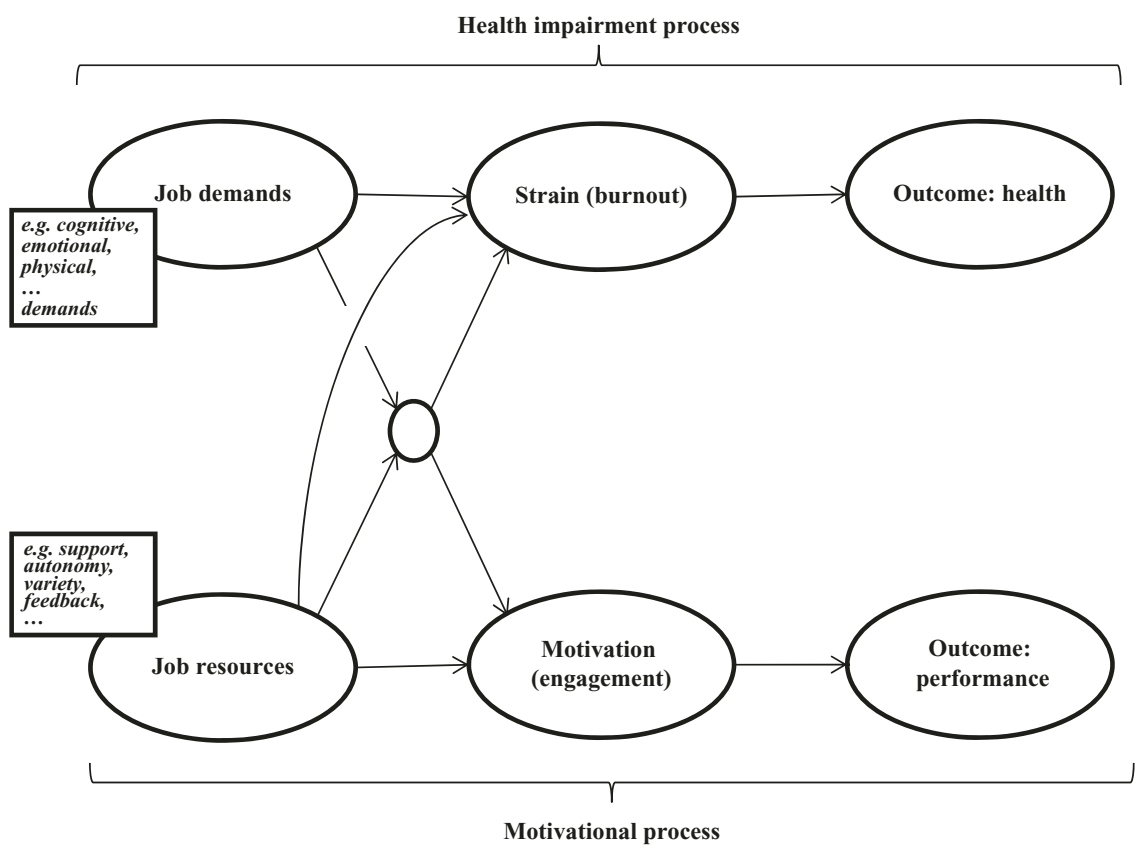

Fig. 11.1 The revised Job Demands-Resources model (based on Schaufeli \& Bakker, 2004, and Bakker \& Demerouti, 2007). For clarity, personal resources are not included 
burnout indicators (exhaustion and withdrawal) tap aspects of strain, whereas the JD-R model of burnout proposed that exhaustion and withdrawal were qualitatively different concepts that were primarily related to demands and resources, respectively. To account for the fact that research on the JD-R model of burnout had found that resources were often associated with withdrawal/cynicism, the revised JD-R model included a direct path from resources to strain. Since the two burnout components (exhaustion/fatigue and withdrawal/cynicism) are usually strongly related (e.g., Taris, Le Blanc, Schaufeli, \& Schreurs, 2005), this modification would seem reasonable, but also one that primarily rests on empirical arguments. Furthermore, similar to the JD-R model of burnout, the revised model proposed that strain would be related to negative outcomes in general, and ill-health in particular (e.g., Melamed, Shirom, Toker, Berliner, \& Shapira, 2006), such as depression, cardiovascular complaints, and psychosomatic complaints. All in all, the health impairment process proposes that high levels of demands and low levels of resources lead to a gradual decrease of mental energy (reflected in terms of the two key components of burnout), which in turn will lead to the development of health-related issues.

The second process links job resources to positive outcomes (especially performance), proposing that this relation is mediated through work engagement. This motivational process starts from the assumption that resources have inherent motivational qualities (Hackman \& Oldham, 1980). The presence of these resources triggers workers' motivation to devote their efforts and abilities to their work tasks. For example, high levels of autonomy, support and feedback (three important resources) are assumed to satisfy workers' basic needs for autonomy, affiliation and competence, respectively, in turn leading to high levels of intrinsic motivation for the tasks at hand (Deci \& Ryan, 2000; Van den Broeck, Vansteenkiste, De Witte, \& Lens, 2008). Ultimately, this will increase levels of work engagement. In turn, high levels of engagement are presumed to lead to positive work outcomes, such as high levels of performance (Demerouti \& Cropanzano, 2010).

The Demands $\times$ Resources Interaction The possible interaction between demands and resources was formally included in the revised JD-R model in 2007, when Bakker and Demerouti explicitly acknowledged that job demands and job resources could interact in affecting worker strain and motivation (Fig.11.1). Referring to Karasek's (1979) Job Demand-Control model, they argued that "the interaction between job demands and job resources is important for the development of job strain and motivation" (2007, p. 217).

Inclusion of Personal Characteristics Probably the most important innovation of the revised JD-R model that has occurred since 2007 is the inclusion of personal characteristics in the model. Initially, neither the JD-R model of burnout nor the revised JD-R model considered factors other than characteristics of the job or the work environment. Since psychological theories on human behavior across various contexts usually emphasize that behavior is a function of the interaction of the environmental context and individual characteristics such as personality, it is not surprising that personal factors were included in the JD-R model. In the model, such factors are considered "personal resources", defined as "positive self-evaluations 
that are linked to resiliency and refer to individuals' sense of their ability to control and impact upon their environment successfully (...) [and] (a) are functional in achieving goals, (b) protect from threats and the associated physiological and psychological costs, and (c) stimulate personal growth and development" (Xanthopoulou, Bakker, Demerouti, \& Schaufeli, 2009, p. 236). In spite of the clear resemblance between this definition of personal resources and the definition of job resources, these two types of resources do not take a similar place in the JD-R model. Although job resources are usually considered as antecedents of strain and motivation (cf. Fig. 11.1), personal resources have been included in several, theoretically and empirically distinct, ways in the model. Schaufeli and Taris (2014) discuss four ways in which personal resources have been integrated into the JD-R model.

The most straightforward way of including such personal characteristics is to consider these as antecedents of strain and motivation. Like job resources, personal resources are defined in terms of positive outcomes, so that - conceptually speaking - they should lead to lower levels of strain/burnout and higher levels of engagement/motivation. Two longitudinal studies have tested this reasoning (Lorente, Salanova, Martinez, \& Schaufeli, 2008, for "mental and emotional competency", and Xanthopoulou et al., 2009, focusing on optimism, self-efficacy, and selfesteem). Both studies supported the assumption that higher levels of personal resources lead to higher levels of well-being (i.e., lower burnout and higher work engagement).

Furthermore, personal resources have been conceptualized as moderators of the associations between job characteristics and outcomes. If personal resources do indeed "protect from threats and the associated physiological and psychological costs", (Xanthopoulou et al., 2009, p. 236), the magnitude of the associations between job characteristics (demands and resources) and outcomes could be dependent on the degree to which workers have access to such personal resources. Specifically, high levels of resources should mitigate the adverse effects of high demands and promote the positive effects of high resources on work outcomes. In line with this reasoning. Brenninkmeijer, Demerouti, Le Blanc, and Van Emmerik (2010) reported that the unfavourable effects of high demands and high levels of interpersonal conflict on exhaustion were stronger for prevention-oriented workers (who focused on safety obligations and avoidance of loss) than for promotionoriented workers (who focused on opportunities and advancement). Similarly, Van den Broeck, Van Ruysseveldt, Smulders, and De Witte (2011) found that the positive effect of high job control on work engagement was relatively strong for intrinsically oriented workers. Thus, both studies suggest that personal resources may moderate the associations between job characteristics and work outcomes.

Additionally, personal resources have been included in the JD-R model as mediators of the relations between job characteristics and outcomes. Job characteristics, especially job resources, could affect workers' personal resources (e.g., their competency, self-efficacy and optimism). In turn, such personal resources could promote work engagement. Several studies have confirmed this idea (Bakker \& Xanthopoulou, 2013; Llorens, Salanova, Schaufeli \& Bakker, 2007; Simbula, Guglielmi, \& Schaufeli, 2011; Van den Broeck et al., 2008; Xanthopoulou, Bakker, 
Demerouti, \& Schaufeli, 2007), adding credence to the notion that personal resources can mediate the associations between work characteristics (especially resources) and work outcomes.

Finally, personal resources could be antecedents of work characteristics. That is, certain personal resources (such as perceived competence, Bandura, 1997) could impinge on workers' (perceptions of their) work environment (both demands and resources), which, in turn, could change work outcomes, such as job satisfaction and performance. In their cross-sectional study on the relations among job resources, personal resources and engagement, Xanthopoulou et al. (2007) found that whereas personal resources (optimism, self-efficacy and self-esteem) mediated the relationship between job resources and engagement, the model with personal resources as an antecedent of job resources fitted the data about equally well. Thus, this study suggests that personal resources may be considered a consequence of job resources, or an antecedent of job resources, or both (i.e. there may be a reciprocal relationship between job and personal resources).

In sum, this short overview shows that (a) personal resources can easily be included in the Job Demands-Resources model; and (b) that personal resources can fulfill different roles in the model: it can be a mediator or a moderator of the relationship between job characteristics and outcomes, an antecedent of strain and motivation, an antecedent of work characteristics, and/or an outcome of work characteristics. The available evidence suggests that relatively stable personal resources (e.g. personality characteristics) are more likely to function as antecedents of work characteristics or outcomes or as moderators of the association between work characteristics and outcomes than relatively malleable characteristics such as self-efficacy, which may be better taken as mediators or even outcomes. However, it is clear that more, preferably longitudinal, research on the role and effects of personal characteristics in the JD-R model, is badly needed.

Evaluation of the Revised Job Demands-Resources Model Since 2004, the revised JD-R model has been applied and tested in a large body of research. Most of this research has provided support for the main effects of job demands on strain and ill-health (the health impairment process) and of job resources on motivation/engagement and performance (among others, Bakker, Demerouti, De Boer, \& Schaufeli, 2003; Hansez \& Chmiel, 2010; Lewig, Xanthopoulou, Bakker, Dollard, \& Metzer, 2007). As regards the magnitude of these main effects, these tend to depend on both the type of job demands/job resources considered as well as the type of outcome. For example, in a cross-sectional study among 12,000 Dutch workers, Bakker, Van Veldhoven, and Xanthopoulou (2010) estimated the effects of 16 combinations of job demands (emotional demands and work load) and job resources (skill utilization, learning possibilities, colleague and leader support, feedback, career opportunities, participation in decision making, and job autonomy) on two outcomes (task enjoyment and commitment). They found that the main effects of these combinations of job characteristics jointly accounted for $6 \%$ to $33 \%$ of the variance in the study outcomes (median 15\%, mean 15\%), with the average amount of variance accounted for in task enjoyment being higher (17.9\%) than that in commitment $(12.4 \%)$. 
Moreover, the findings of these cross-sectional studies were also replicated longitudinally (Akkermans, Brenninkmeijer, Van den Bossche, Blonk, \& Schaufeli, 2013; Hakanen, Schaufeli, \& Ahola, 2008). However, other longitudinal studies failed to support the assumptions of the revised JD-R model (Brauchli, Schaufeli, Jenny, Füllemann, \& Bauer, 2013; Ouweneel, Le Blanc, \& Schaufeli, 2012; Seppäla et al., 2014), perhaps because engagement and burnout tend to be relatively stable across time, leaving little variance to be accounted for across time (see Mäkikangas, Kinnunen, Feldt, \& Schaufeli, 2016, for a discussion).

Apart from these main effects, the demands $\times$ resources interaction has also frequently been tested, both cross-sectionally and longitudinally. However, this interaction has proved to be a fickle phenomenon. Whereas some studies revealed the expected interaction effects (Bakker, Hakanen, Demerouti, \& Xanthopoulou, 2007; Bakker, Van Veldhoven, \& Xanthopoulou, 2010), other studies provided only limited evidence (e.g., Brough et al., 2013). Moreover, even if statistically significant, demand $\times$ resource interactions tend to be of relatively little practical relevance. For instance, although 28 out of the 32 demand $\times$ resource interactions tested in Bakker, Van Veldhoven, and Xanthopoulou's (2010) study among 12,000 Dutch workers were statistically significant, these accounted on average for only an additional $0.5 \%$ of the variance in the outcome variables beyond what was already accounted for by the main effects of the demands and resources involved.

Summarizing, the evidence discussed above shows strong cross-sectional evidence for main effects of demands and resources on strain (especially burnout) and motivation (engagement), respectively. The longitudinal evidence is somewhat less convincing. Moreover, demands $\times$ resources interaction effects tend to be unreliable for small to moderately-sized samples and are usually of small magnitude. However, although not all predictions of the JD-R model have unequivocally been confirmed, it is fair to conclude that the model can successfully be applied as a framework for research on the work-related antecedents of stress and well-being.

\subsection{Job Demands, Job Resources, and Teacher Stress and Well-Being}

Both the Job Demands-Resources model of burnout and the revised JD-R model were developed for use in a general context, across a wide range of occupations. Indeed, the fact that they are relatively independent from the specific job context in which they are applied is one of the main attractions of these models. In the past, these models have also frequently been used to examine job stress (burnout) and motivation (engagement) among educators. In this section, we present a focused literature review, aiming to identify the most important results obtained with these models on the task-specific, organizational and personal antecedents and consequences of teacher stress and motivation. 


\subsubsection{Approach}

Previous reviews on the JD-R model (Bakker \& Demerouti, 2007; Schaufeli \& Taris, 2014; Taris \& Schaufeli, 2016) were screened for possibly relevant studies. Moreover, a literature search in the PsycInfo and ERIC databases was conducted to identify additional studies, using "job demands", "job resources", "school”, "university", and "educator" and "teacher", as search terms. In order to be eligible, studies were required to present an empirical study (a) in which either the JDR-model of burnout or the revised JD-R model was used as the theoretical framework; (b) in which both job demands and job resources were included; (c) in which at least some of the outcomes studied could be classified as motivational and/or health-related outcomes; (d) where participants educated students at either the primary, secondary or tertiary level; (e) that was written in English; and (f) that was published in 2014 or earlier. Relevant studies were screened and the following information was recorded: (1) the nature of the sample (design, sample size, type of participants); (2) the job demands and job/personal resources included in the study; (3) the outcomes studied; and (4) the study findings (main effects and interaction effects).

\subsubsection{Results}

In total, 10 studies were retrieved. Table 11.1 presents a detailed overview of the main characteristics of these studies and Table 11.2 summarizes their main findings. As Table 11.1 shows, the studies in this review were published between 2005 and 2012. The samples were collected in several countries, including Australia, South Africa, Finland, Spain, Italy and the Netherlands. Three studies (2, 6, and 7) contained a relatively heterogeneous group of educators, including teachers from the primary, secondary and tertiary (college/university) levels. Six studies focused on one specific group of teachers (teachers at either the secondary or the tertiary level). One study (5) focused on school principals: although these participants were teachers, it is unclear to which degree they were actually involved in classroom teaching. Sample sizes ranged from 146 to 3,753, with half of the samples not exceeding 300 participants. Moreover, only three studies (8-10) employed a longitudinal design (note that study 9 and 10 focused on different variables measured in the same sample); in these cases only two waves of data were collected.

Job Demands and Job Resources Table 11.1 also presents the job demands and job resources that were included in these studies. Regarding demands, most studies included a measure of quantitative job demands (also termed "overload" or "work pressure") (studies 1, 3-4, 6-10). Studies 1, 7 and 9 also included qualitative job demands such as mental, emotional and/or physical job demands. Although workhome conflict is often considered an outcome of high job demands, it was included as a job demand in studies 1, 3 and 5. Role conflict/ambiguity was measured in two studies ( 9 and 10 - note that this is the same sample), and inequity and interpersonal 


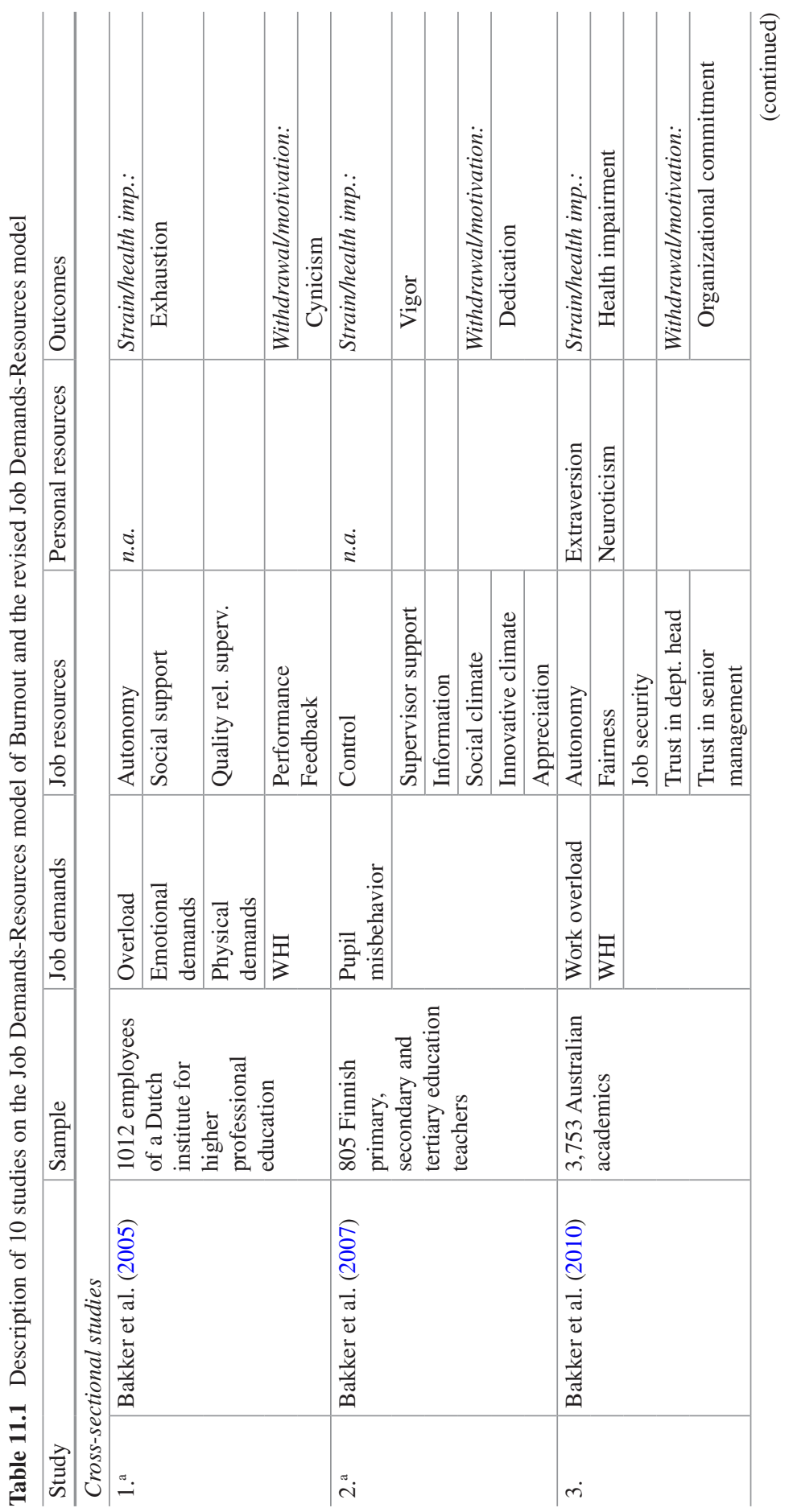




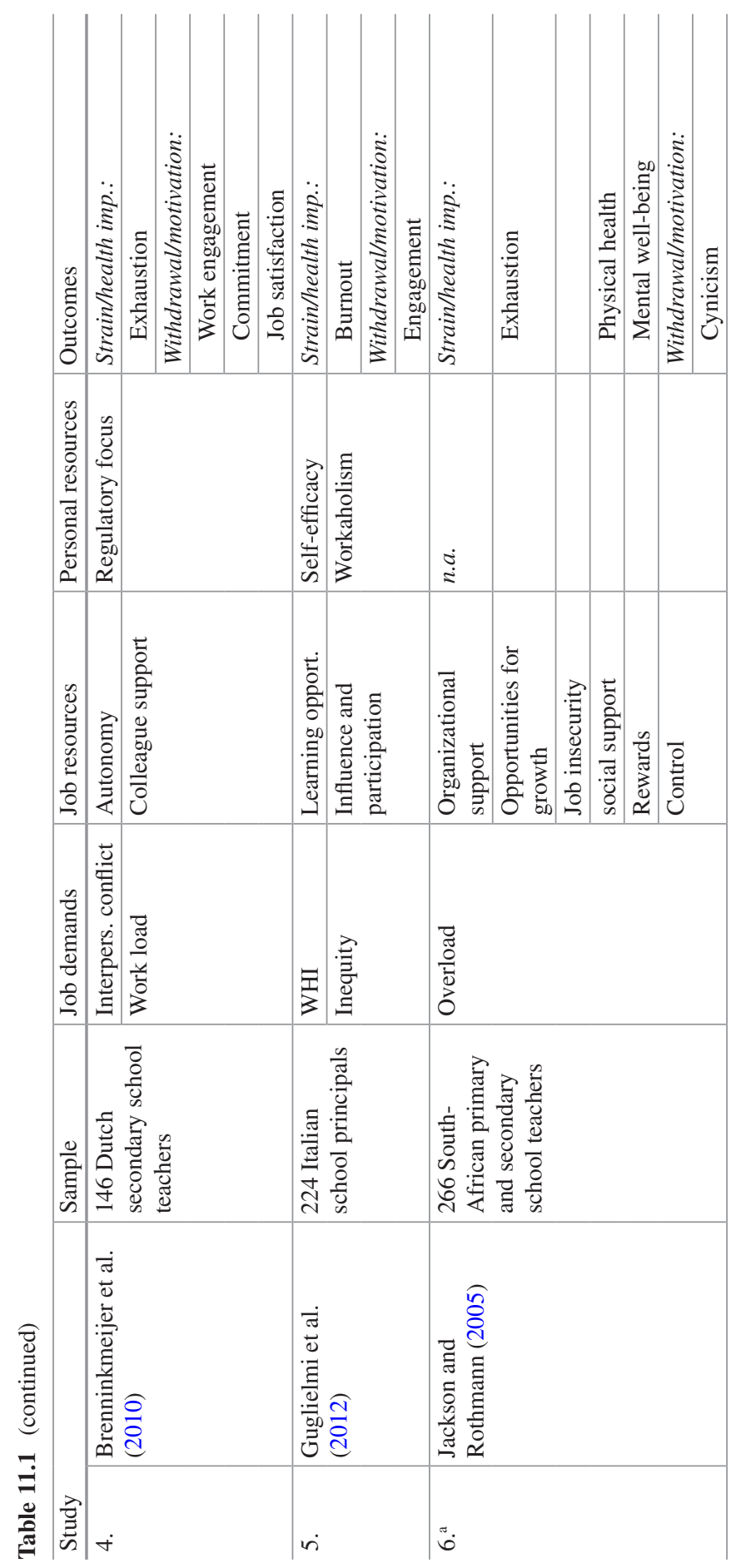




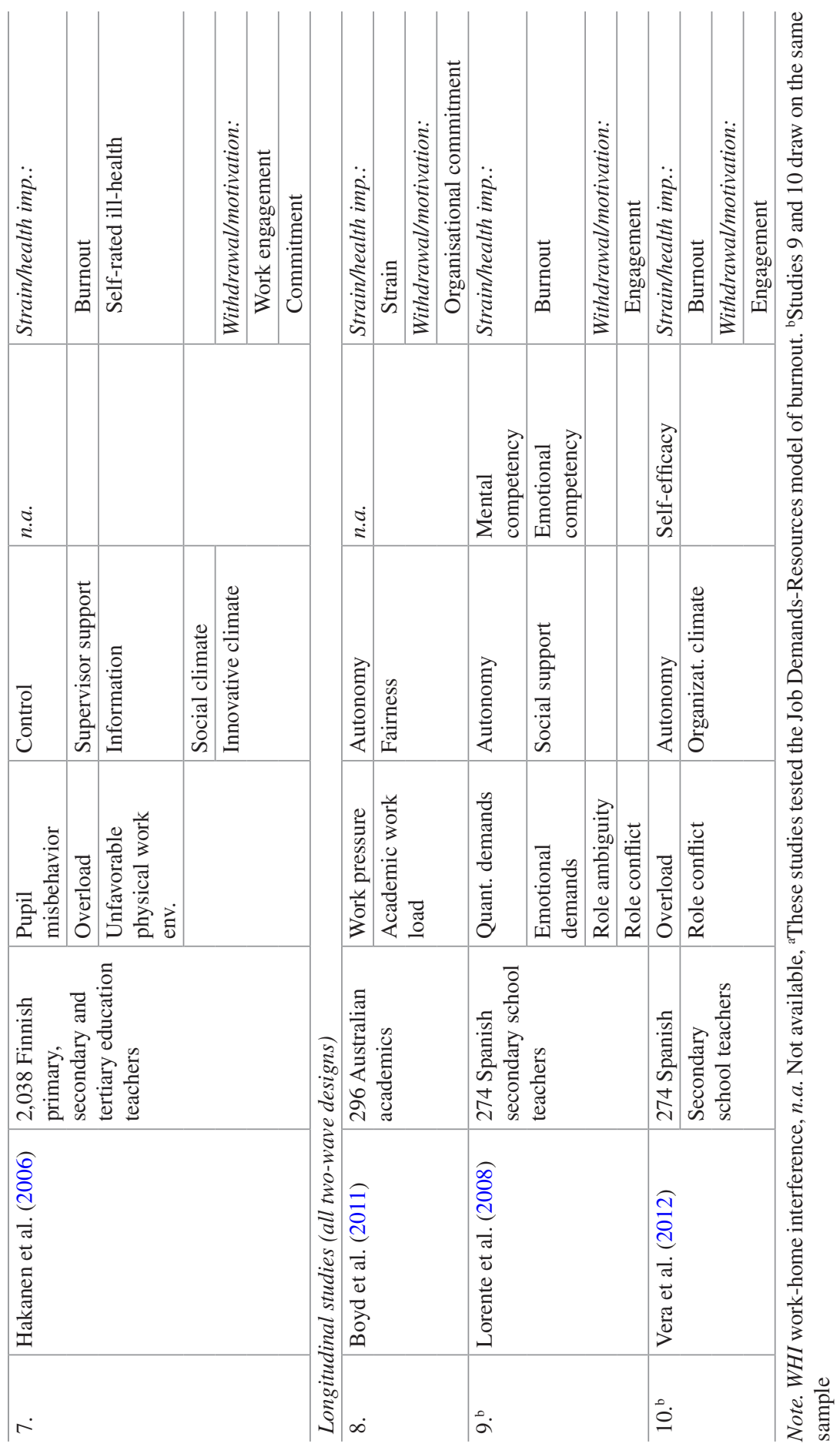


Table 11.2 Main findings of 10 studies on the Job Demands-Resources model of Burnout and the revised Job Demands-Resources model

\begin{tabular}{|c|c|}
\hline Study & Main findings \\
\hline \multicolumn{2}{|c|}{ Cross-sectional studies } \\
\hline \multirow[t]{4}{*}{$1 .^{\mathrm{a}}$} & Adverse effects of demands on strain/health (and withdrawal/motivation) \\
\hline & Favorable effects of all resources on withdrawal/motivation (and strain/health) \\
\hline & $\begin{array}{l}18 \text { out of } 32 \text { possible demands } \times \text { resources interactions significant ( } 7 \text { involving } \\
\text { autonomy) }\end{array}$ \\
\hline & $\begin{array}{l}\text { Conclusion: motivational and health impairment processes supported; no evidence for } \\
\text { separate processes; moderate support for demand } \times \text { resource interaction }\end{array}$ \\
\hline \multirow[t]{4}{*}{ 2. ${ }^{a}$} & Adverse effects of demands on strain/health (and withdrawal/motivation) \\
\hline & Favorable effects of resources on withdrawal/motivation (and strain/health) \\
\hline & $\begin{array}{l}13 \text { out of } 18 \text { possible demands } \times \text { resources interactions significant; no interactions with } \\
\text { control, other interactions with resources generally significant (adverse effects of high } \\
\text { demands are stronger for low resources) }\end{array}$ \\
\hline & $\begin{array}{l}\text { Conclusion: motivational and health impairment processes supported; no evidence for } \\
\text { separate processes; moderate support for demand } \times \text { resource interaction }\end{array}$ \\
\hline \multirow[t]{6}{*}{3.} & Adverse effects of demands on strain/health \\
\hline & Favorable effects of resources on strain/health \\
\hline & Favorable effects of resources on withdrawal/motivation \\
\hline & Neuroticism affects demands and impairment (i.e., is an antecedent of demands) \\
\hline & Extraversion affects resources and commitment (i.e., is an antecedent of resources) \\
\hline & $\begin{array}{l}\text { Conclusion: motivational and health impairment processes supported; personal } \\
\text { resources are antecedents of demands and resources }\end{array}$ \\
\hline \multirow[t]{3}{*}{4.} & $\begin{array}{l}\text { Adverse effects of demands on strain/health; these effects are stronger for participants } \\
\text { with a prevention focus }\end{array}$ \\
\hline & $\begin{array}{l}\text { Favorable effects of high resources on motivation/withdrawal are stronger for } \\
\text { participants with a low promotion focus }\end{array}$ \\
\hline & $\begin{array}{l}\text { Conclusion: motivational and health impairment processes supported; personal } \\
\text { resources moderate effects of job characteristics on outcomes }\end{array}$ \\
\hline \multirow[t]{6}{*}{5.} & Adverse effects of demands on strain/health \\
\hline & Adverse effects of workaholism on strain/health are partially mediated by demands \\
\hline & Favorable effects of job resources on motivation/withdrawal \\
\hline & $\begin{array}{l}\text { Favorable effects of self-efficacy on motivation/withdrawal are partially mediated by } \\
\text { job resources }\end{array}$ \\
\hline & Favorable effects of job resources on strain/health \\
\hline & $\begin{array}{l}\text { Conclusion: motivational and health impairment processes supported; personal } \\
\text { resources are antecedents of demands and resources }\end{array}$ \\
\hline \multirow[t]{5}{*}{$6 .^{\mathrm{a}}$} & Adverse effects of demands on strain/health \\
\hline & Favorable effects of job resources on strain/health \\
\hline & Adverse effects of demands on motivation/withdrawal \\
\hline & Favorable effects of job resources on motivation/withdrawal \\
\hline & $\begin{array}{l}\text { Conclusion: motivational and health impairment processes supported; no evidence for } \\
\text { separate processes }\end{array}$ \\
\hline
\end{tabular}


Table 11.2 (continued)

\begin{tabular}{|c|c|}
\hline Study & Main findings \\
\hline \multirow[t]{4}{*}{7.} & Adverse effects of job demands on strain/health \\
\hline & Favorable effects of job resources on strain/health \\
\hline & Favorable effects of job resources on motivation/withdrawal \\
\hline & Conclusion: motivational and health impairment processes supported \\
\hline \multicolumn{2}{|c|}{ Longitudinal studies (two-wave designs) } \\
\hline \multirow[t]{3}{*}{8.} & Favorable effects of job resources on later strain/health \\
\hline & Favorable effects of job resources on later motivation/withdrawal \\
\hline & Conclusion: motivational process supported; no support for health impairment process \\
\hline \multirow[t]{4}{*}{ 9. ${ }^{\mathrm{b}}$} & $\begin{array}{l}\text { After controllling for relevant time } 1 \text { indicators of strain/health or motivation/ } \\
\text { withdrawal: }\end{array}$ \\
\hline & Adverse effects of job demands on later strain/health (and later motivation/withdrawal) \\
\hline & Favorable effect of job demands (overload) on later motivation/withdrawal (dedication) \\
\hline & Conclusion: health impairment process supported; no support for motivational process \\
\hline \multirow[t]{5}{*}{$10 .^{\mathrm{b}}$} & Cross-sectional adverse effects of job demands on strain/health \\
\hline & Favorable effect of self-efficacy on later burnout is mediated by job demands \\
\hline & Cross-sectional favorable effects of job resources on motivation/withdrawal \\
\hline & $\begin{array}{l}\text { Favorable effect of self-efficacy on later motivation/withdrawal is mediated by job } \\
\text { resources }\end{array}$ \\
\hline & $\begin{array}{l}\text { Conclusion: health impairment and motivational processes are supported cross- } \\
\text { sectionally; self-efficacy is a precursor of later demands and resources }\end{array}$ \\
\hline
\end{tabular}

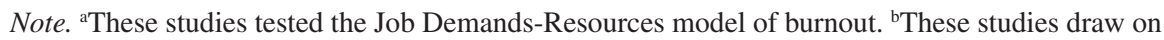
the same sample

conflict were included in one study each (study 5 and 4, respectively). Finally, two studies ( 2 and 7 ,) included a job demand that can be considered characteristic for the teaching profession, namely pupil misbehavior.

Regarding the job resources, virtually all studies (except 5) tapped job autonomy/control. Various forms of social support were also frequently measured (study $1,2,4,6,7,9-10)$. All other resources were included only once or twice. Interestingly, many of these resources refer to aspects of interpersonal relationships at work, such as social climate (which overlaps to some degree, but not entirely, with social support), appreciation, fairness, and trust. Other resources were performance feedback, information, innovative climate, opportunities for growth/learning, rewards, and influence/participation in decision making.

It is interesting to see that although the JD-R model in its various guises assumes that relevant job characteristics may vary across jobs (Bakker \& Demerouti, 2007), virtually all demands and resources studied in the teaching context could equally well have been studied in other occupations. Indeed, the three most "popular" job characteristics studied in the educator context (job control, various types of demands, and social support) are also the key factors in Karasek's much older DemandControl-Support model (Karasek \& Theorell, 1990). This might be taken to mean that either a teacher's job is fairly standard (having few specific demands/resources) or that, so far, researchers have not felt the need to take full advantage of the model's 
flexibility in terms of examining demands/resources relevant and specific to the teaching context. ${ }^{1}$

Personal Resources Five studies (3-5, 9-10, all published in 2008 or later) included measures of personal resources, with studies 5 and 10 focusing on selfefficacy and the remaining studies examining personality characteristics such as extraversion and neuroticism (3) and regulatory focus (4), or skills/behavior-like concepts, such as mental and emotional competencies (9) or workaholism (5). The position of these concepts in the JD-R model varies. Personal resources are considered antecedents of demands and resources $(3,5,9-10)$ or moderators of the associations between demands/resources and outcomes (4). However, since most of these studies employed cross-sectional designs (with the exception of studies 9-10), ideas concerning the causal order of the concepts must necessarily rest on theoretical grounds.

Outcomes Consistent with the various versions of the JD-R model, Table 11.1 focuses on two sets of outcome variables: strain/health-related outcomes on the one hand, and motivation/withdrawal-related outcomes on the other. Therefore, the outcomes presented in Table 11.1 were assigned to either of these two clusters. Because the JD-R model of burnout and the revised JD-R model differ in their classification of the cynicism/depersonalization dimension of the burnout concept (respectively considering cynicism as an indicator of withdrawal/lack of motivation or as an indicator of strain/ill-health), the classification of the burnout dimensions in Table 11.1 was contingent upon the theoretical framework that was tested in a particular study.

As Table 11.1 shows, seven studies included (at least one dimension of) burnout (1, 4-7, 9-10). Studies 1 and 6 tested the JD-R model of burnout, taking exhaustion as an indicator of strain/health impairment and cynicism as a measure of withdrawal/motivation. The other studies considered burnout as a measure of strain/illhealth. Interestingly, study 2 also employed the JD-R model of burnout, but included vigor and dedication (two dimensions of the engagement concept) as indicators of strain and withdrawal, respectively. The remaining studies employed measures of physical and mental health, self-rated ill-health, and stress-related and psychosomatic complaints as indicators of strain/health impairment. Regarding the indicators of withdrawal/motivation, studies 4, 5, 7 and 9-10 focused on work engagement. Organizational commitment was employed in studies 3, 4, 7-8. No other indicators of withdrawal/motivation were studied.

Main Findings Table 11.2 presents the main findings of the 10 identified studies and discusses these in terms of "demands" and "resources" in general, since the findings obtained for specific demands (resources) tended to be similar across demands (resources). Thus, study findings can meaningfully be discussed for

\footnotetext{
${ }^{1}$ Note that although the three most frequently studied job characteristics in the teacher context using the JD-R model have also been studied in other models such as Karasek and Theorell's (1990) Demand-Control(-Support) model, the items used to tap these concepts could well be specifically tailored towards the educator context. However, this does not affect our general conclusion that the basic concepts studied in the JD-R model have also been studied in other approaches.
} 
demands and resources in general, rather than separately for each specific demand or resource. Further, consistent with the various versions of the JD-R model, Table 11.2 focuses on two sets of outcome variables: health and well-being on the one hand, and motivation/withdrawal-related concepts on the other. In this way the two central processes in the JD-R model (the health impairment process and the motivational process) can conveniently be examined. Finally, attention is given to both possible demands $\times$ resource interactions, and the role of personal characteristics.

The JD-R Model of Burnout It is important to note that three of the four oldest studies in this table (studies 1, 2 and 6) tested the Job Demands-Resources model of burnout, not the revised JD-R model. All these studies found that high demands were associated with high levels of strain and ill-health, and that high resources were associated with lower levels of withdrawal/motivation. Although this is consistent with the health impairment and motivational processes proposed in the JD-R model, it should be noted that the model also proposes that these processes are more or less independent from each other. However, all three studies show that high resources and low demands were also associated with low levels of strain and high levels of motivation, respectively, which goes against the assumptions of the JD-R model of burnout. Apparently, the indicators of strain/ill-health and motivation/ withdrawal relate in a very similar way to the demands and resources included in these studies, up to the point where they cannot be distinguished in terms of their correlates. Since these outcomes are both part of the overall burnout concept, these findings suggest that exhaustion and cynicism are actually indicators of the same underlying concept (i.e, burnout). This is in line with the assumptions of the revised JD-R model; the JD-R model of burnout thus received only limited support in these studies.

Demand $\times$ Resource Interactions Interestingly, although studies 1,2 and 6 set out to test the JD-R model of burnout (in which the demands $\times$ resources interaction was considered unimportant, cf. Demerouti et al., 2001), studies 1 and 2 did test for interaction effects. In conjunction, these two studies tested 50 interactions, 31 of which $(61 \%)$ reached significance. ${ }^{2}$ Overall, these interactions showed that the adverse effects of high demands on the outcomes were weaker in the presence of high resources. Focusing on specific demands $\times$ resources interactions, it is noteworthy that 7 of the 18 significant interactions in study 1 involved job control, suggesting that control - as proposed earlier in Karasek's (1979) Demand-Control model - is an important buffer of the adverse effects of high demands. However, the only resource in study 2 that was not involved in any significant interactions also involved control. Apparently the findings for interactions involving control are

\footnotetext{
${ }^{2}$ The Bakker et al. $(2005,2007)$ studies did not correct for the effect of multiple testing (e.g., using Bonferroni correction). Moreover, these tests were not statistically independent since the interactions within a particular study were all based on the same set of observations and involved the same - sometimes highly correlated - variables. Consequently, the number of statistically significant interactions $(61 \%)$ is likely to have been estimated optimistically.
} 
inconsistent in this research. As none of the other studies included in this review reported tests of demand $\times$ resource interaction effects, overall the evidence for interactions in the context of educator stress is moderately strong at best.

The Revised JD-R Model: The Health Impairment and Motivational Processes The health impairment process implies that adverse strain/health-related outcomes are primarily associated with high job demands and, possibly, also by low levels of resources. This assumption is fully supported in studies 3-5, 7, 9 and 10 (with study 9 offering longitudinal evidence, and with only study 8 offering no support for this process). The motivational process holds that motivation/withdrawal is primarily related to job resources (but not to job demands). This assumption is fully supported in studies 3-5, 7-8 and 10, with study 8 offering longitudinal support. Overall, it can be concluded that the support for both processes among educators is strong, although it should be noted that only study 8 and 9 offered longitudinal support.

The Revised JD-R Model: Personal Resources Studies 3-5 and 9-10 also included personal resources. These studies (especially 3, 5, and 10) showed that personal resources (neuroticism, extraversion, workaholism and self-efficacy) may be considered antecedents of job demands and job resources (with study 10 offering longitudinal evidence). Study 4 showed that regulatory focus - examining whether participants attempt to avoid loss or to maximize gains - moderated the effects of demands/resources on the outcomes, such that favorable effects of particular job characteristics were most likely to occur for those seeking to maximize their gains. Study 9 provided no evidence for any significant role of personal resources (mental and emotional competencies). Overall, these studies provide some support for personal resources as antecedents or moderators in the revised JD-R model, but the evidence is piecemeal and in need of replication, preferably using longitudinal designs.

\subsection{Discussion}

In this chapter, we have discussed the origins and different versions of the Job Demands-Resources model. Further, we provided an overview of the findings obtained with this model in the context of educator stress, health and motivation. The current version of the JD-R model holds that ill-health (e.g., exhaustion) is primarily related to high demands (the health impairment process), whereas motivation and withdrawal is primarily related to low resources (the motivational process). Further, there should be an interaction between demands and resources. Personal resources have been incorporated in the JD-R model as antecedents, moderators, mediators and/or outcomes.

Our review of 10 studies published between 2005 and 2012 that were conducted in the educator context provided weak support for the oldest version of the model, the JD-R model of burnout. Although exhaustion was indeed related to demands and 
cynicism/withdrawal to resources as predicted by the JD-R model, these outcomes were also affected by resources and demands, respectively. This suggests that the health impairment and motivational processes cannot be distinguished, at least not for burnout in the teaching context. Rather, these findings provided strong support for the current revised version of the JD-R model, supporting both the health impairment and motivational processes. Although two early studies which tested the JD-R model of burnout revealed a substantial number of demand $\times$ resource interactions, the findings of these studies were in some respects inconsistent and were not replicated in later research in the educator context. Finally, the review provided some support for personal characteristics as antecedents of demands and resources and weak support for moderator effects of personal resources. All in all, it can be concluded that the evidence collected in the educator context was largely consistent with the assumptions of the revised JD-R model.

This does not necessarily mean that there is strong support for the JD-R model or that it has contributed significantly to understanding educator stress, motivation and well-being. Firstly, methodological limitations impose limits to the strength of the evidence for the JD-R model. The large majority of studies uses cross-sectional, self-report data, making it impossible to draw strong conclusions on the causal directions of the associations in the JD-R model. This not only applies to research in the educator context, but also to research using the JD-R model in other occupational contexts (Schaufeli \& Taris, 2014; Taris \& Schaufeli, 2016). However, taking all available evidence into account, it seems fair to say that the model's two central assumptions concerning the health impairment and motivational processes have received strong support, also among educators.

Secondly, one may wonder whether the JD-R model has yielded insights on the antecedents of teacher stress and well-being that could not have been obtained using earlier models, such as Karasek and Theorell's (1990) Job Demand-Control-Support model or Siegrist's (1996) Effort-Reward Imbalance model. Looking at the job characteristics that have been studied as antecedents of teacher stress and motivation using the JD-R model, it is noteworthy that the large majority of demands and resources that have been examined in the context of educator stress are factors (such as quantitative work load, autonomy, support) that take a central place in other approaches as well. In this sense, application of the JD-R model has generated no major new insights into the antecedents of educator stress. However, this is perhaps less due to the model itself than to the researchers using the model who have focused on job characteristics of general importance rather than on educator-specific job characteristics. Looking at the outcomes studied, the two main outcomes examined in the model are burnout and work engagement. Burnout has been studied using other approaches as well, but it is interesting to see that work engagement - as a relatively novel concept - is often studied in the context of the JD-R model. Indeed, it might be argued that the JD-R model derives part of its popularity from the fact that it is the model of choice to study work engagement - a concept that has had strong appeal to those working in the area of work and organizational psychology (Schaufeli, 2014). 
However, the JD-R model does contribute to understanding educator stress and motivation as a heuristic integrative framework par excellence. It allows researchers to conveniently classify, combine, integrate and extend different theories, processes, concepts and findings, spurring research on traditional issues such as the role of personal resources in health and well-being as well as on novel topics such as job crafting as an antecedent (and perhaps consequence) of job characteristics, stress and performance (e.g., Tims \& Bakker, 2010). In this respect, the heuristic potential of the JD-R model has not fully been exploited as yet. If researchers are to complement the generic variables with educator-specific job characteristics (e.g., pupil misbehavior, stressful interactions with parents and "red tape"), the flexibility of the JD-R model will most likely facilitate a fuller understanding of the antecedents of educator stress.

\section{References}

Akkermans, J., Brenninkmeijer, V., Van den Bossche, S. N. J., Blonk, R. W. B., \& Schaufeli, W. B. (2013). Young and going strong? A longitudinal study on occupational health among young employees of different educational levels. Career Development International, 18, 416-435. doi:10.1108/CDI-02-2013-0024.

Alarcon, G. M. (2011). A meta-analysis of burnout with job demands, resources, and attitudes. Journal of Vocational Behavior, 79, 549-562. doi:10.1016/j.jvb.2011.03.007.

Bakker, A. B., Boyd, C. M., Dollard, M., Gillespie, N., Winefield, A. H., \& Stough, C. (2010). The role of personality in the job demands-resources model: A study of Australian academic staff. Career Development International, 15, 622-636. doi: 10.1108/13620431011094050

Bakker, A. B., \& Demerouti, E. (2007). The job demands-resources model: State of the art. Journal of Managerial Psychology, 22, 309-328. doi:10.1108/02683940710733115.

Bakker, A. B., Demerouti, E., De Boer, E., \& Schaufeli, W. (2003). Job demands and job resources as predictors of absence duration and frequency. Journal of Vocational Behavior, 62, 341-356. doi: 10.1016/S0001-8791(02)00030-1

Bakker, A. B., Demerouti, E., \& Euwema, M. C. (2005). Job resources buffer the impact of job demands on burnout. Journal of Occupational Health Psychology, 10, 170-180. doi:10.1037/1076-8998.10.2.170.

Bakker, A. B., Demerouti, E., Taris, T. W., Schaufeli, W. B., \& Schreurs, P. J. G. (2003). A multigroup analysis of the Job Demands-Resources Model in four home care organizations. International Journal of Stress Management, 10, 16-38. doi:10.1037/1072-5245.10.1.16.

Bakker, A. B., Hakanen, J. J., Demerouti, E., \& Xanthopoulou, D. (2007). Job resources boost work engagement, particularly when job demands are high. Journal of Educational Psychology, 99, 274-284. doi:10.1037/0022-0663.99.2.274.

Bakker, A. B., Van Veldhoven, M., \& Xanthopoulou, D. (2010). Beyond the Demand-Control Model: Thriving on high job demands and resources. Journal of Personnel Psychology, 9, 3-16. doi:10.1027/1866-5888/a000006.

Bakker, A. B., \& Xanthopoulou, D. (2013). Creativity and charisma among female leaders: The role of resources and work engagement. International Journal of Human Resource Management, 24, 2760-2779. doi:10.1080/09585192.2012.751438.

Bandura, A. (1997). Self-efficacy: The exercise of control. New York: Freeman.

Boyd, C. M., Bakker,A. B., Pignata, S., Winefield, A.H., Gillespie, N., \& Stough, C. (2011). A longitudinal test of the Job Demands-Resources model among Australian university academics. Applied Psychology: An International Review, 60, 112-140. doi:10.1111/j.1464-0597.2010.00429.x. 
Brauchli, R., Schaufeli, W. B., Jenny, G. J., Füllemann, D., \& Bauer, G. F. (2013). Disentangling stability and change in job resources, job demands, and employee well-being: A three-wave study on the job demands-resources model. Journal of Vocational Behavior, 83, 117-129. doi:10.1016/j.jvb.2013.03.003.

Brenninkmeijer, V., Demerouti, E., Le Blanc, P., \& Van Emmerik, H. (2010). Regulatory focus at work: The moderating role of regulatory focus in the Job Demands-Resources model. Career Development International, 15, 708-728. doi:10.1108/13620431011094096.

Brough, P. M., Timms, C., Siu, Q., Kalliath, T., O’Driscoll, M.P., Sit, C.H.P., Lo, D., \& Lu, C. (2013). Validation of the job demands-resources model in cross-national samples: Crosssectional and longitudinal predictions of psychological strain and work engagement. Human Relations, 66, 1311-1335. doi: 10.11772F0018726712472915

De Jonge, J., \& Dormann, C. (2006). Stressors, resources, and strain at work: A longitudinal test of the triple-match principle. Journal of Applied Psychology, 91, 1359-1374. doi:10.1037/0021-9010.91.5.1359.

Deci, E. L., \& Ryan, R. M. (2000). The "what" and "why" of goal pursuits: Human needs and the self-determination of behavior. Psychological Inquiry, 11, 319-338. doi:10.1207/ S15327965PLI1104_01.

Demerouti, E., Bakker, A. B., Nachreiner, F., \& Schaufeli, W. B. (2001). The job demands-resources model of burnout. JournalofAppliedPsychology, 86,499-512.doi:10.1037/0021-9010.86.3.499.

Demerouti, E., \& Cropanzano, R. (2010). From thought to action: Employee work engagement and job performance. In A. B. Bakker \& M. P. Leiter (Eds.), Work engagement: A handbook of essential theory and research (pp. 147-163). New York: Psychology Press.

Diestel, S., \& Schmidt, K. H. (2012). Lagged mediator effects of self-control demands on psychological strain and absenteeism. Journal of Occupational and Organizational Psychology, 85, 556-578. doi:10.1111/j.2044-8325.2012.02058.x.

Frese, M., \& Zapf, D. (1994). Action as the core of work psychology: A German approach. In H. C. Triandis, M. D. Dunnette, \& L. M. Hough (Eds.), Handbook of industrial and organizational psychology (Vol. 4, pp. 271-340). Palo Alto: Consulting Psychologists Press.

Guglielmi, D., Simbula, S., Schaufeli, W. B., \& Depolo, M. (2012). Self-efficacy and workaholism as initiators of the job demands-resources model. Career Development International, 17, 375-389. doi:10.1108/13620431211255842.

Hackman, J. R., \& Oldham, G. R. (1980). Work redesign. Reading, MA: Addison Wesley.

Hakanen, J., Bakker, A. B., \& Schaufeli, W. B. (2006). Burnout and work engagement among teachers. Journal of School Psychology, 43, 495-513. doi:10.1016/j.jsp.2005.11.001.

Hakanen, J. J., Schaufeli, W. B., \& Ahola, K. (2008). The Job Demands-Resources model: A threeyear cross-lagged study of burnout, depression, commitment, and work engagement. Work \& Stress, 22, 224-241. doi:10.1080/02678370802379432.

Hansen, N., Sverke, M., \& Naswall, K. (2009). Predicting nurse burnout from demands and resources in three acute care hospitals under different forms of ownership: A cross-sectional questionnaire survey. International Journal of Nursing Studies, 46, 95-106. doi:10.1016/j. ijnurstu.2008.08.002.

Hansez, I., \& Chmiel, N. (2010). Safety behavior: Job demands, job resources, and perceived management commitment to safety. Journal of Occupational Health Psychology, 15, 267-278. doi:10.1037/a0019528.

Hockey, G. R. J. (1997). Compensatory control in the regulation of human performance under stress and high workload: A cognitive energetical framework. Biological Psychology, 45, 73-93. doi:10.1016/S0301-0511(96)05223-4.

Jackson, L., \& Rothmann, S. (2005). Work-related well-being of educators in a district of the North-West Province. Perspectives in Education, 23, 107-122.

Karasek, R. (1979). Job demands, job decision latitude and mental strain: Implications for job redesign. Administrative Science Quarterly, 24, 285-306. doi:10.2307/2392498.

Karasek, R. A., \& Theorell, T. (1990). Healthy work: Stress, productivity, and the reconstruction of working life. New York: Basic books. 
Knardahl, S., \& Ursin, H. (1985). Sustained activation and the pathophysiology of hypertension and coronary heart disease. In J. F. Orlebeke, G. Mulder, \& L. J. P. van Doornen (Eds.), Psychophysiology of cardiovascular control: Models, methods, and data (pp. 151-167). New York: Plenum.

Lee, R. T., \& Ashforth, B. E. (1996). A meta-analytic examination of the correlates of the three dimensions of job burnout. Journal of Applied Psychology, 81, 123-133. doi:10.1037/0021-9010.81.2.123.

Lewig, K. A., Xanthopoulou, D., Bakker, A. B., Dollard, M., \& Metzer, J. C. (2007). Burnout and connectedness among Australian volunteers: A test of the Job Demands-Resources model. Journal of Vocational Behavior, 71, 429-445. doi:10.1016/j.jvb.2007.07.003.

Llorens, S., Salanova, M., Schaufeli, W. B., \& Bakker, A. (2007). Does a positive gain spiral of resources, efficacy beliefs and engagement exist? Computers in Human Behavior, 23, 825-841. doi:10.1016/j.chb.2004.11.012.

Lorente, L., Salanova, M., Martinez, I., \& Schaufeli, W. B. (2008). Extension of the Job Demands Resources model in the prediction of burnout and engagement among teachers over time. Psicotema, 20, 354-360.

Mäkikangas, A., Kinnunen, U., Feldt, T., \& Schaufeli, W. B. (2016). The longitudinal development of employee well-being: A systematic review. Work \& Stress, 30. doi:10.1080/02678373.201 5.1126870 .

Maslach, C., Jackson, S. E., \& Leiter, M. (1996). Maslach Burnout Inventory (3rd ed.). Palo Alto, CA: Consulting Psychologists Press.

Melamed, A., Shirom, A., Toker, S., Berliner, S., \& Shapira, I. (2006). Burnout and risk of cardiovascular disease: Evidence, possible causal paths, and promising research directions. Psychological Bulletin, 132, 327-353. doi:10.1037/0033-2909.132.3.327.

Ouweneel, E., Le Blanc, P. M., \& Schaufeli, W. B. (2012). Don't leave your heart at home: Gain cycles of positive emotions, resources, and engagement at work. Career Development International, 17, 537-556. doi:10.1108/13620431211280123.

Schaufeli, W. B. (2014). What is engagement? In C. Truss, R. Delbridge, K. Alfes, A. Shantz, \& E. Soane (Eds.), Employee engagement in theory and practice (pp. 15-35). London: Routledge.

Schaufeli, W. B., \& Bakker, A. B. (2010). The conceptualization and measurement of work engagement. In A. B. Bakker \& M. P. Leiter (Eds.), Work engagement: A handbook of essential theory and research (pp. 10-24). New York: Psychology Press.

Schaufeli, W. B., \& Bakker, A. B. (2004). Job demands, job resources, and their relationship with burnout and engagement: A multi-sample study. Journal of Organizational Behavior, 25, 293 315. doi:10.1002/job. 248.

Schaufeli, W. B., \& Taris, T. W. (2005). The conceptualization and measurement of burnout: Common ground and worlds apart. Work \& Stress, 19, 256-262. doi:10.1080/02678370500385913.

Schaufeli, W. B., \& Taris, T. W. (2014). A critical review of the Job Demands-Resources Model: Implications for improving work and health. In G. Bauer \& O. Hämmig (Eds.), Bridging occupational, organizational and public health (pp. 43-68). Dordrecht, The Netherlands: Springer.

Seppäla, P., Hakanen, J., Mauno, S., Perhoniemi, R., Tolvanen, A., \& Schaufeli, W. B. (2014). Stability and change model of job resources and job engagement: A seven-year, three-wave follow-up study. European Journal of Work and Organizational Psychology, 24, 360-375. doi :10.1080/1359432X.2014.910510.

Semmer, N. K., \& Beehr, T. A. (2014). Job control and social aspects of work. In M. C. W. Peeters, J. de Jonge, \& T. W. Taris (Eds.), An introduction to contemporary work psychology (pp. 171195). Malden: Wiley-Blackwell.

Siegrist, J. (1996). Adverse health effects of high-effort/low-reward conditions. Journal of Occupational Health Psychology, 1, 27-41. doi:10.1037/1076-8998.1.1.27.

Simbula, S., Guglielmi, D., \& Schaufeli, W. B. (2011). A three wave study on job resources, selfefficacy and work engagement among Italian school teachers. European Journal of Work and Organizational Psychology, 20, 285-305. doi:10.1080/13594320903513916.

Taris, T. W. (2006). Bricks without clay: On urban myths in occupational health psychology. Work \& Stress, 20, 99-104. doi:10.1080/02678370600893410. 
Taris, T. W., Le Blanc, P. M., Schaufeli, W. B., \& Schreurs, P. J. G. (2005). Are there causal relationships between the dimensions of the Maslach Burnout Inventory? A review and two longitudinal tests. Work \& Stress, 19, 238-255. doi:10.1080/02678370500270453.

Taris, T. W., \& Schaufeli, W. B. (2016). The Job Demands-Resources model. In S. Clarke, T. M. Probst, F. W. Guldenmund, \& J. Passmore (Eds.), The Wiley-Blackwell handbook of the psychology of occupational safety and workplace health (pp. 157-180). Oxford: Wiley-Blackwell.

Tims, M., \& Bakker, A. B. (2010). Job crafting: Towards a new model of individual job redesign. South African Journal of Industrial Psychology, 36. doi:10.4102/sajip.v36i2.841.

Van den Broeck, A., De Cuyper, N., De Witte, H., \& Vansteenkiste, M. (2010). Not all demands are equal: Differentiating job hindrances and job challenges in the Job Demands-Resources model. European Journal of Work and Organizational Psychology, 19, 735-759.

Van den Broeck, A., Van Ruysseveldt, J., Smulders, P., \& De Witte, H. (2011). Does an intrinsic value orientation strengthen the impact of job resources? A perspective from the Job DemandsResources model. European Journal of Work and Organizational Psychology, 20, 581-609.

Van den Broeck, A., Vansteenkiste, M., De Witte, H., \& Lens, W. (2008). Explaining the relationships between job characteristics, burnout, and engagement: The role of basic psychological need satisfaction. Work \& Stress, 22, 277-294. doi:10.1080/02678370802393672.

Vera, M., Salanova, M., \& Lorente, L. (2012). The predicting role of self-efficacy in the Job Demands-Resources model: A longitudinal study. Estudios de Psicología, 33, 167-178.

Warr, P. (2007). Work, happiness, and unhappiness. Mahwah: Lawrence Erlbaum.

Xanthopoulou, D., Bakker, A. B., Demerouti, E., \& Schaufeli, W. B. (2007). The role of personal resources in the job demands-resources model. International Journal of Stress Management, 14, 121-141. doi:10.1037/1072-5245.14.2.121.

Xanthopoulou, D., Bakker, A. B., Demerouti, E., \& Schaufeli, W. B. (2009). Work engagement and financial returns: A diary study on the role of job and personal resources. Journal of Organizational and Occupational Psychology, 82, 183-200. doi:10.1348/096317908X285633. 